\title{
The up-regulation of type I interferon receptor gene plays a key role in hepatocellular carcinoma cells in the synergistic antiproliferative effect by 5-fluorouracil and interferon- $\alpha$
}

\author{
SHINJI OIE ${ }^{1,3}$, MAYUMI ONO ${ }^{1,2,4}$, HIROHISA YANO ${ }^{4,5}$, YUICHIRO MARUYAMA ${ }^{1,4}$, \\ TADAFUMI TERADA ${ }^{3}$, YUJI YAMADA ${ }^{3,4}$, TAKATO UENO ${ }^{4,6}$, MASAMICHI KOJIRO $^{4,5}$, \\ KAZUYUKI HIRANO ${ }^{7}$ and MICHIHIKO KUWANO ${ }^{1,4}$
}

\author{
${ }^{1}$ Station-II for Collaborative Research, ${ }^{2}$ Department of Medical Biochemistry, Graduate School of Medical Sciences, \\ Kyushu University, 3-1-1 Maidashi, Higashi-ku, Fukuoka 812-8582; ${ }^{3}$ Drug Discovery Laboratory, TAIHO \\ Pharmaceutical Co., Ltd., 1-27 Misugidai, Hanno-shi, Saitama 357-8527; ${ }^{4}$ Research Center for Innovative \\ Cancer Therapy, ${ }^{5}$ Department of Pathology, ${ }^{6}$ The Second Department of Internal Medicine, Kurume University \\ School of Medicine, 67 Asahi-machi, Kurume, Fukuoka 830-0011; ${ }^{7}$ Laboratory of Pharmaceutics, \\ Gifu Pharmaceutical University, 5-6-1 Mitahora-higashi, Gifu-shi, Gifu 502-8585, Japan
}

Received March 10, 2006; Accepted April 26, 2006

\begin{abstract}
Combination therapy with interferon (IFN)- $\alpha$ and 5-fluorouracil (5-FU) has been reported to show an improved therapeutic efficacy in patients with advanced hepatocellular carcinoma (HCC) but the mechanism behind this has not been completely elucidated. We examined the molecular events underlying the antiproliferative effects of IFN- $\alpha$ and 5-FU in combination using six human HCC cell lines. When the antiproliferative effects of administering IFN- $\alpha$ and 5-FU together were analyzed using isobolograms, we found that the cell lines could be divided into two groups: the S-group containing three cell lines, which showed synergistic effects, and the A-group, containing the remaining three cell lines, which showed additive effects. Real-time RT-PCR and Western blot analyses revealed that the expression levels of type I IFN
\end{abstract}

Correspondence to: Dr Shinji Oie, Station-II for Collaborative Research, Kyushu University, 3-1-1 Maidashi, Higashi-ku, Fukuoka 812-8582, Japan

E-mail: oh9906ie@qa2.so-net.ne.jp

Abbreviations: IFN- $\alpha$, interferon $\alpha$; 5-FU, 5-fluorouracil; HCC, hepatocellular carcinoma; IFNAR1, type I IFN receptor subunit 1; IFNAR2, type I IFN receptor subunit 2; FdUMP, 5-fluoro2'deoxyuridine-5'-monophosphate; TS, thymidylate synthase; TP, thymidine phosphorylase; DPD, dihydropyrimidine dehydrogenase; OPRT, orotate phosphoribosyl transferase; UP, uridine phosphorylase; TK, thymidine kinase; RT-PCR, reverse transcription-polymerase chain reaction

Key words: interferon- $\alpha, 5$-fluorouracil, combination therapy, synergism, interferon receptor, hepatocellular carcinoma receptor subunits, IFNAR1 and IFNAR2, were specifically up-regulated by 5-FU in all three cell lines of the S-group with the exception of IFNAR2 in one cell line, but not in those of the A-group. IFN- $\alpha$ modulated the protein expression levels of six enzymes regulating sensitivity to 5-FU, but none of them were down- or up-regulated in the same way in all members of the S- or A-group. In conclusion, the 5-FUinduced modulation of IFN receptor expression could play a pivotal role in the therapeutic efficacy of IFN- $\alpha$ combined with 5-FU. Measuring the expression levels of IFN receptors, and their ability to be up-regulated, may be a promising method for selecting HCC patients for this type of combination therapy.

\section{Introduction}

Hepatocellular carcinoma (HCC), the most common primary liver cancer, is one of the most frequent and aggressive malignant tumors, and its incidence is increasing. The surgical resection of hepatic lesions is the most effective treatment for patients with HCC, and local therapeutic approaches, such as transcatheter arterial embolization (1), percutaneous transhepatic ethanol injection (2), microwave coagulation (3), and radiofrequency ablation (4) have also been reported to be effective. However, these therapies are still not effective for patients with advanced HCC, who are often not suitable for surgery and whose 5-year survival rate is extremely low (5). One chemotherapeutic strategy is combined chemotherapy with 5-fluorouracil (5-FU) and interferon (IFN)- $\alpha$. Monden and colleagues have reported a beneficial therapeutic effect in a patient with recurrent HCC and multiple lung and bone metastases (6-8). However, this combined treatment was accompanied by increased toxicity, as manifested by an elevated incidence of mucositis and neurological and hematological side effects (9). It is therefore important to understand 
the exact mechanism of this combination therapy so that patients likely to respond can be selected and unnecessary side effects can be avoided.

5-FU has two major antitumor mechanisms: one involves its active metabolite 5-fluoro-2'-deoxyuridine-5'-monophosphate (FdUMP), inhibiting the activity of thymidylate synthase (TS) and consequently DNA synthesis; the other is related to the incorporation of 5-FU metabolite into RNA and DNA, thereby disrupting normal RNA processing and function. The sensitivity of cancer cells to 5-FU is often influenced by the enzymes affecting 5-FU metabolism, including dihydropyrimidine dehydrogenase (DPD), orotate phosphoribosyl transferase (OPRT), thymidine phosphorylase (TP), uridine phosphorylase (UP), and thymidine kinase (TK). In contrast, IFNs are divided into type I and type II. The human type I IFN family is composed of at least 14 structurally related IFN- $\alpha$ subtypes and single IFN- $\beta$ and IFN- $\omega$ subtypes. Type I IFNs have various biological activities, including antiviral, anti-proliferative, immunomodulatory (10-12), and antiangiogenic effects $(13,14)$, mediated by the type I IFN receptor. This receptor is composed of two functional transmembrane subunits, type I IFN receptor subunit 1 (IFNAR1) and subunit 2 (IFNAR2), cooperating to form a high-affinity receptor for all type I IFNs $(15,16)$. IFNAR2 is the major binding subunit and IFNAR1 is necessary for the tight binding. Of these receptor molecules, the expression levels of the type I IFN receptor were closely correlated with the response rates to IFN treatment in patients with chronic hepatitis C (17), and overexpression of the IFNAR2 markedly increased the antiproliferative activity of IFNs and their capacity to induce apoptosis (18), suggesting that the type I IFN receptor is a key molecule for the antitumor activity of IFN- $\alpha$.

Concerning possible mechanisms behind IFN- $\alpha$ and 5-FU showing improved therapeutic efficacy, increased FdUMP concentrations, decreased protein level of TS, an increase in TS inhibition rate and TP activity, and an alteration in 5-FU pharmacokinetics by combined IFN- $\alpha$ have been reported (19-24). Eguchi et al have reported that augmentation of the antitumor effect of 5-FU by IFN- $\alpha$ might in part be attributable to the up-regulation of $\mathrm{p} 27^{\mathrm{Kip} 1}$ blocking cell cycle progression (25). However, none of these theories provide a consistent mechanism for the exact rationale of this combination therapy. Furthermore, almost all studies have assumed that IFN- $\alpha$ plays a role in modulating the antitumor activity of 5-FU.

In this study, we provide evidence that the modulation of IFN receptor expression by 5-FU is specifically associated with the improved efficacy rather than the cellular modulation of the enzymes that regulate the sensitivity to $5-\mathrm{FU}$ by IFN- $\alpha$.

\section{Materials and methods}

Drugs. Natural human IFN- $\alpha$ was purchased from Otsuka Pharmaceutical Co., Ltd. (OIF, Tokyo, Japan) and 5-FU was purchased from Kyowa Hakko Kogyo Co., Ltd. (5-FU Injection 250 Kyowa, Tokyo, Japan).

Cell lines. HCC cell lines, KIM-1, KYN-1, KYN-2, KYN-3, HAK-1A and HAK-1B (26-30), were grown in Dulbecco's modified Eagle's medium (Nissui Seiyaku Co., Tokyo, Japan) with $10 \%$ fetal bovine serum (FBS) (FETALCLONE III,
Hyclone, UT, USA) in a humidified atmosphere of $5 \% \mathrm{CO}_{2}$ at $37^{\circ} \mathrm{C}$.

Antiproliferation test. Cells were seeded into 96-well plates at 1,000 cells/ $0.1 \mathrm{ml} /$ well and incubated overnight. On the following day, $100 \mu \mathrm{l}$ aliquot containing IFN- $\alpha$ and 5-FU was added and cultured for a further 5 days. In study of scheduledependent synergy, HCC cells were seeded into 12-well plates at 5,000 cells $/ 1 \mathrm{ml} /$ well. On the following day, $1-\mathrm{ml}$ aliquot containing drugs was added. After a further 3 days, culture medium was exchanged for fresh medium including another drug and cultured for a further 3 days. The number of viable cells was estimated by activity of cellular dehyrogenases using WST-8 reagent (Cell Counting Kit-8, DOJINDO, Kumamoto, Japan) (31).

Isobologram analysis. To analyze the mode of interaction between 5-FU and IFN- $\alpha$, the combined doses that reduced cell growth by $50 \%$ were plotted as isobolograms, according to the method of Steel and Peckham (32). The envelope of additivity surrounded by mode I (heteroaddition), IIa and IIb (isoaddition) curves, was constructed based on the doseresponse curves of IFN- $\alpha$ and 5-FU alone. Thus, when the data points for the combined drugs fell within this envelope, the combined effect was judged to be additive. When the points fell in the area under the envelope of additivity, the combined effect was judged as synergistic, because in this case, $50 \%$ inhibition was produced by a lower concentration than predicted on an additive basis.

cDNA preparation and quantitative real-time RT-PCR. Total RNA was extracted using Isogen (Nippon Gene Co., Ltd., Tokyo, Japan) and reverse transcribed using a reverse transcription system (Promega Corp., Madison, WI) according to the manufacturer's instructions. RT-PCR was performed with an ABI PRISM 7300 (PE Applied Biosystems, Foster City, $\mathrm{CA}$ ). The sequences of the primers and probes are shown in Table I, and those for IFNAR1, IFNAR2 and glyceraldehyde3-phosphate dehydrogenase (GAPDH) were purchased from Applied Biosystems.

Western blotting. HCC cells were cultured with various concentrations of 5-FU or IFN- $\alpha$. Total protein was extracted using protein extraction reagent (M-PER ${ }^{\mathrm{TM}}$, Pierce, Rockford, IL) supplemented with protease inhibitors (Halt ${ }^{\mathrm{TM}}$ protease inhibitor cocktail kit, Pierce). Cell lysates were subjected to SDS-PAGE and transferred to Immobilon-P transfer membranes (Millipore, Bedford, MA). After blocking, membranes were probed with anti-TS, -OPRT and -TP monoclonal and anti-DPD polyclonal antibodies (a gift from TAIHO Pharmaceutical Co., Ltd., Tokyo, Japan), monoclonal antibody against TK (abcam, Cambridge, UK), polyclonal antibodies against IFNAR1, IFNAR2 and UP (Santa Cruz Biotechnology, Santa Cruz, CA). The proteins were visualized using HRP-conjugated antibodies followed by enhanced chemiluminescence (Pierce). The intensity of luminescence was quantified using an image analysis system (LAS-1000, Fuji Film, Tokyo, Japan).

Silencing IFNAR1 and IFNAR2 genes. Stealth ${ }^{\mathrm{TM}}$ RNAis (Invitrogen $^{\text {TM }}$ Life Technologies, San Diego, CA) were used 
Table I. Probe and primer pair sequences for six factors regulating 5-FU sensitivity.

\begin{tabular}{|c|c|c|}
\hline Gene & & Sequences \\
\hline \multirow{3}{*}{$\mathrm{TS}^{\mathrm{a}}$} & Probe: & 5'-(FAM)TTCAGCTTCAGCGAGAACCCAGA(TAMRA)-3' \\
\hline & Forward primer: & 5'-GAATCACATCGAGCCACTGAAA-3' \\
\hline & Reverse primer: & 5'-CAGCCCAACCCCTAAAGACTGA-3' \\
\hline \multirow{3}{*}{$\mathrm{DPD}^{\mathrm{b}}$} & Probe: & 5'-(FAM)TGCCCTCACCAAAACTTTCTCTCTTGATAAGGA(TAMRA)-3' \\
\hline & Forward primer: & 5'-AATGATTCGAAGAGCTTTTGAAGC-3' \\
\hline & Reverse primer: & 5'-GTTCCCCGGATGATTCTGG-3' \\
\hline \multirow{3}{*}{$\mathrm{OPRT}^{\mathrm{c}}$} & Probe: & 5' (FAM)CTCCTTATTGCGGAAATGAGCTCCACC(TAMRA)-3' \\
\hline & Forward primer: & 5'-TCCTGGGCAGATCTAGTAAATGC-3' \\
\hline & Reverse primer: & 5'-TGCTCCTCAGCCATTCTAACC-3' \\
\hline \multirow{3}{*}{$\mathrm{TP}^{\mathrm{d}}$} & Probe: & 5'-(FAM)CAGCCAGAGATGTGACAGCCACCGT(TAMRA)-3' \\
\hline & Forward primer: & 5'-CCTGCGGACGGAATCCT-3' \\
\hline & Reverse primer: & 5'-GCTGTGATGAGTGGCAGGCT-3' \\
\hline \multirow{3}{*}{$\mathrm{UP}^{\mathrm{e}}$} & Probe: & 5'-(FAM)TGCTCCAACGTCACTATCATCCGCAT(TAMRA)-3' \\
\hline & Forward primer: & 5'-TGACTGCCCAGGTAGAGACTATCC-3' \\
\hline & Reverse primer: & 5'-AGACCTATCCCACCAGAAGTGC-3' \\
\hline \multirow{3}{*}{$\mathrm{TK}^{\mathrm{f}}$} & Probe: & 5'-(FAM)TGGCCTGGATTCACGCCCTCTTG(TAMRA)-3' \\
\hline & Forward primer: & 5'-AGCCTTGGCCCACACTGA-3' \\
\hline & Reverse primer: & 5'-CCAGAGGTAGGAAGGGCTTTG-3' \\
\hline
\end{tabular}

${ }^{a}$ Thymidylate synthase; ${ }^{b}$ dihydropyrimidine dehydrogenase; ${ }^{c}$ orotate phosphoribosyl transferase; ${ }^{d}$ thymidine phosphorylase; ${ }^{e}$ uridine phosphorylase; and thymidine kinase.
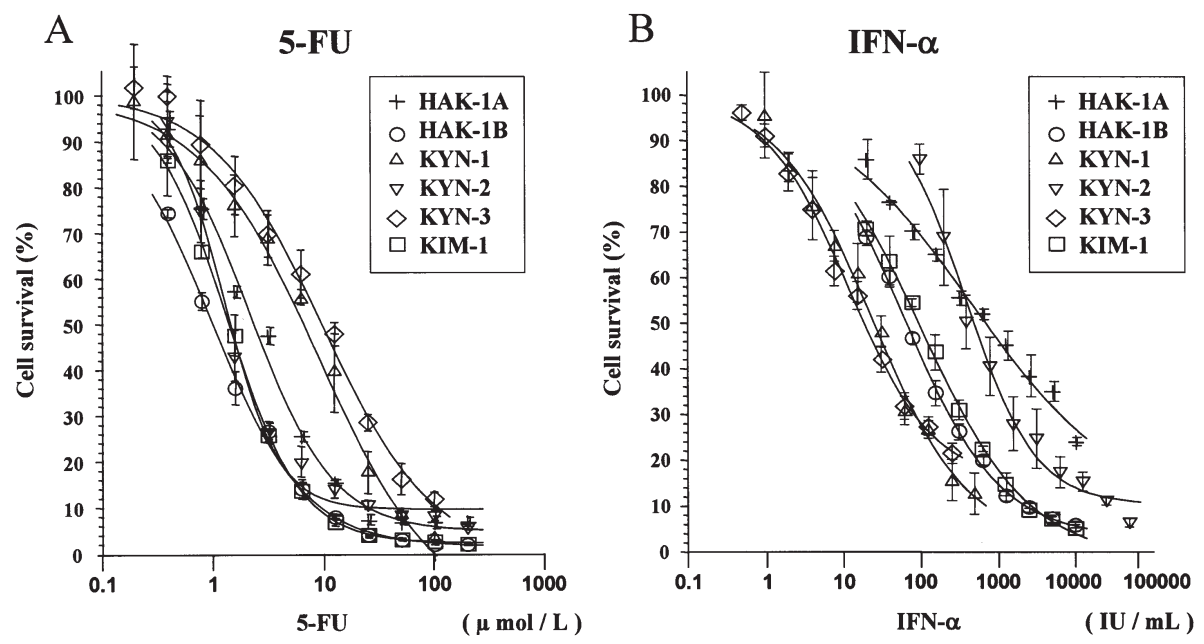

Figure 1. Antiproliferative effects of IFN- $\alpha$ and 5-FU in six HCC cell lines, HAK-1A, HAK-1B, KYN-1, KYN-2, KYN-3, and KIM-1. Cells were exposed to drugs for 5 days. Curves show the fitted dose-response curves for 5-FU (A) and IFN- $\alpha$ (B). Assays were carried out in quadruplicate. Data points represent the mean \pm SD of the cell survival ratio relative to that of untreated cells, taken as $100 \%$. Experiments were repeated twice with essentially similar results.

to knock down IFNAR1 (j03171_stealth_189) and IFNAR2 (x89772_stealth_1054) expression. Sub-confluent KYN-1 cells were cultured overnight in Opti-MEM I medium, then $40 \mathrm{nmol} / \mathrm{l}$ siRNA and Lipofectamine ${ }^{\mathrm{TM}} 2000$ (Invitrogen $^{\mathrm{TM}}$ Life Technologies) were applied according to the manufacturer's instructions. After $4 \mathrm{~h}$, cells were harvested from the culture plates and seeded into 96-well plates. After a further 8-h incubation, IFN- $\alpha$ was applied and cells were cultured for 5 more days. The numbers of cells were estimated by WST-8 method (31).

\section{Results}

Antiproliferative effects of IFN- $\alpha$ and 5-FU in six HCC cell lines. When the antiproliferative effects of IFN- $\alpha$ and 5-FU on six HCC cell lines were examined, the growth inhibition seen 
Table II. Relative mRNA expression levels of type I IFN receptor subunits and six factors regulating sensitivity to 5-FU in six HCC cell lines.

\begin{tabular}{|c|c|c|c|c|c|c|c|c|c|c|}
\hline \multirow[b]{2}{*}{ Cell line } & \multicolumn{7}{|c|}{ Relative mRNA levels a } & \multirow[b]{2}{*}{$\mathrm{TK}^{\mathrm{i}}$} & \multicolumn{2}{|c|}{$\mathrm{IC}_{50}{ }^{\mathrm{j}}$} \\
\hline & IFNAR $^{\text {b }}{ }^{2}$ & IFNAR2 $^{c}$ & $\mathrm{TS}^{\mathrm{d}}$ & $\mathrm{DPD}^{\mathrm{e}}$ & OPRT $^{f}$ & $\mathrm{TP}^{\mathrm{g}}$ & $\mathrm{UP}^{\mathrm{h}}$ & & $\begin{array}{l}\text { IFN- } \alpha \\
(\mathrm{IU} / \mathrm{ml})\end{array}$ & $\begin{array}{l}5-\mathrm{FU} \\
(\mu \mathrm{mol} / \mathrm{l})\end{array}$ \\
\hline HAK-1A & 23 & 5 & 100 & 1 & 100 & 6 & 16 & 91 & 700 & 2.3 \\
\hline HAK-1B & 100 & 100 & 15 & 59 & 84 & 100 & 100 & 43 & 66 & 1.0 \\
\hline KYN-1 & 99 & 54 & 67 & 100 & 71 & 15 & 94 & 99 & 25 & 7.2 \\
\hline KYN-2 & 5 & 13 & 9 & 4 & 38 & 34 & 2 & 92 & 490 & 1.4 \\
\hline KYN-3 & 27 & 14 & 66 & 13 & 55 & 31 & 36 & 92 & 19 & 9.6 \\
\hline KIM-1 & 38 & 27 & 20 & 87 & 42 & 55 & 19 & 100 & 94 & 1.4 \\
\hline
\end{tabular}

${ }^{a}$ The mRNA levels were examined by quantitative real-time RT-PCR and normalized with GAPDH. Relative mRNA level shows the average of the ratio relative to the highest level in six HCC cell lines of 100 in respective factor in triplicate determinations. ${ }^{b}$ Type I interferon receptor subunit 1 ; ${ }^{c}$ type I interferon receptor subunit 2 ; ${ }^{\mathrm{d}}$ thymidylate synthase; ${ }^{\mathrm{e}}$ dihydropyrimidine dehydrogenase; ${ }^{\mathrm{f}}$ orotate phosphoribosyl

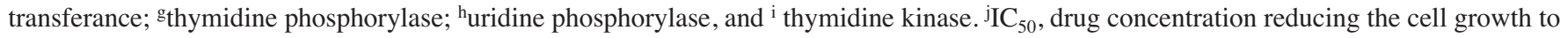
$50 \%$ of that of non-treated cells. Cytotoxicity tests were carried out in quadruplicate.
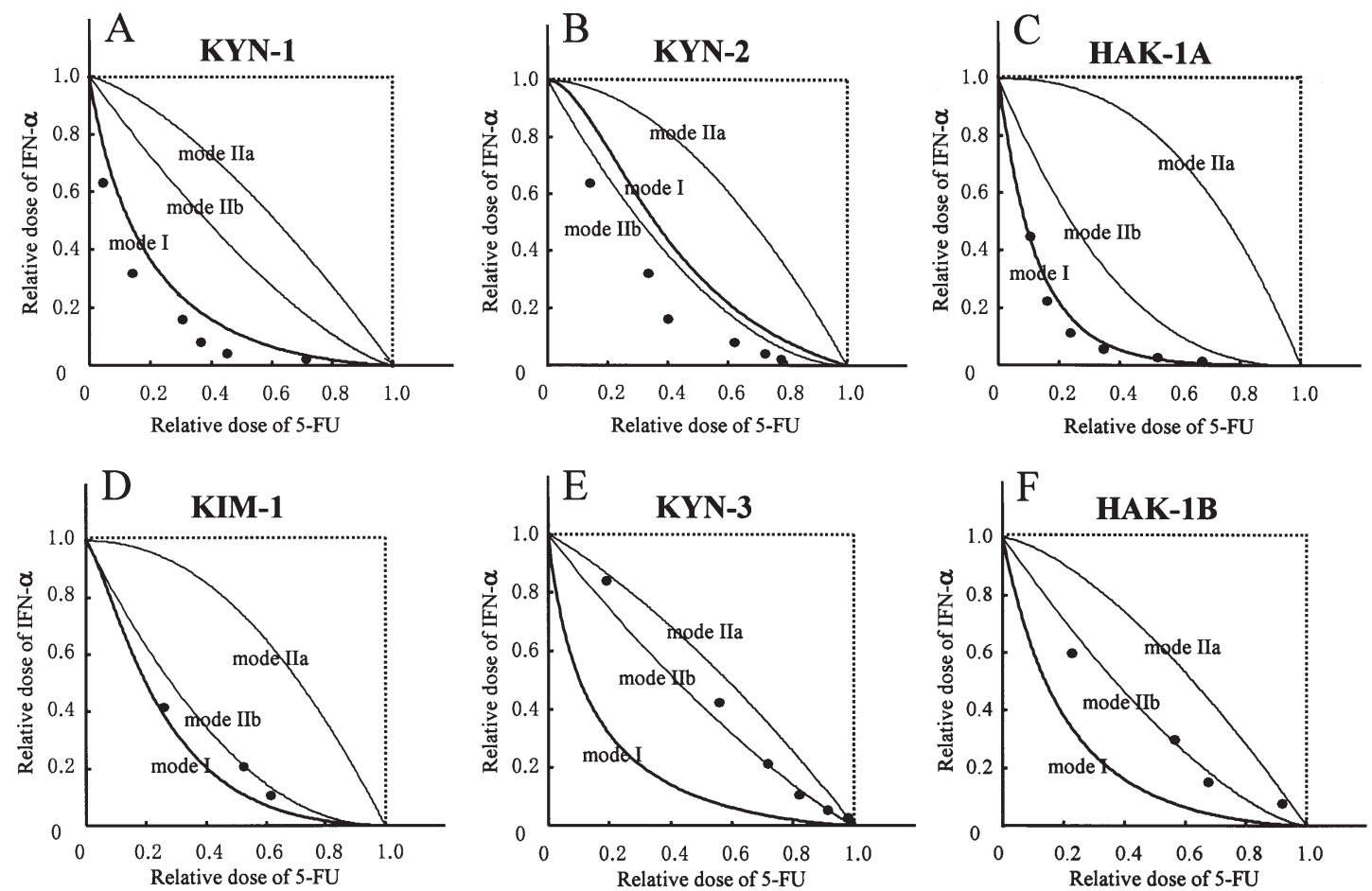

Figure 2. Combination effects of IFN- $\alpha$ and 5-FU. Isobologram analysis of IFN- $\alpha$ and 5-FU against six HCC cell lines. Cells were exposed to IFN- $\alpha$ and 5-FU for 5 days simultaneously. The area surrounded by the outer 2 curves of Mode I, IIa and IIb curves is the envelope of additivity. Relative doses of the drugs were calculated as concentration of 5 -FU/IC $\mathrm{IC}_{50}$ of 5-FU and concentration of IFN- $\alpha / \mathrm{IC}_{50}$ of IFN- $\alpha$. Closed circles represent combined concentrations of 5-FU and IFN- $\alpha$ that inhibited cell growth by $50 \%$. Assays were carried out in quadruplicate. Experiments were repeated twice with essentially similar results.

in all HCC cell lines was dose-dependent (Fig. 1). The HCC cell lines showed varied sensitivities to $\mathrm{IFN}-\alpha$, with $\mathrm{IC}_{50}$ values over a 25 -fold range, from 19 to $700 \mathrm{IU} / \mathrm{ml}$ (Table II). KIM-1, KYN-1, KYN-3, and HAK-1B were highly sensitive to IFN- $\alpha$ with $\mathrm{IC}_{50}$ values below $100 \mathrm{IU} / \mathrm{ml}$, while HAK-1A and KYN-2 appeared to be more resistant with $\mathrm{IC}_{50}$ values of 700 and 490 $\mathrm{IU} / \mathrm{ml}$, respectively. KYN-1 and KYN-3 responded weakly to 5-FU with $\mathrm{IC}_{50}$ values of 7.2 and $9.6 \mu \mathrm{mol} / 1$, respectively, while the remaining four HCC cell lines were approximately three times more sensitive to 5-FU.

Expression of type I IFN receptor and factors regulating 5-FU sensitivity in six HCC cell lines. Table II shows the relative levels of basal mRNAs for IFNAR1, IFNAR2 and factors regulating sensitivity to 5-FU, with an arbitrary maximum value of 100. The mRNA levels of IFNAR1 were highest in 


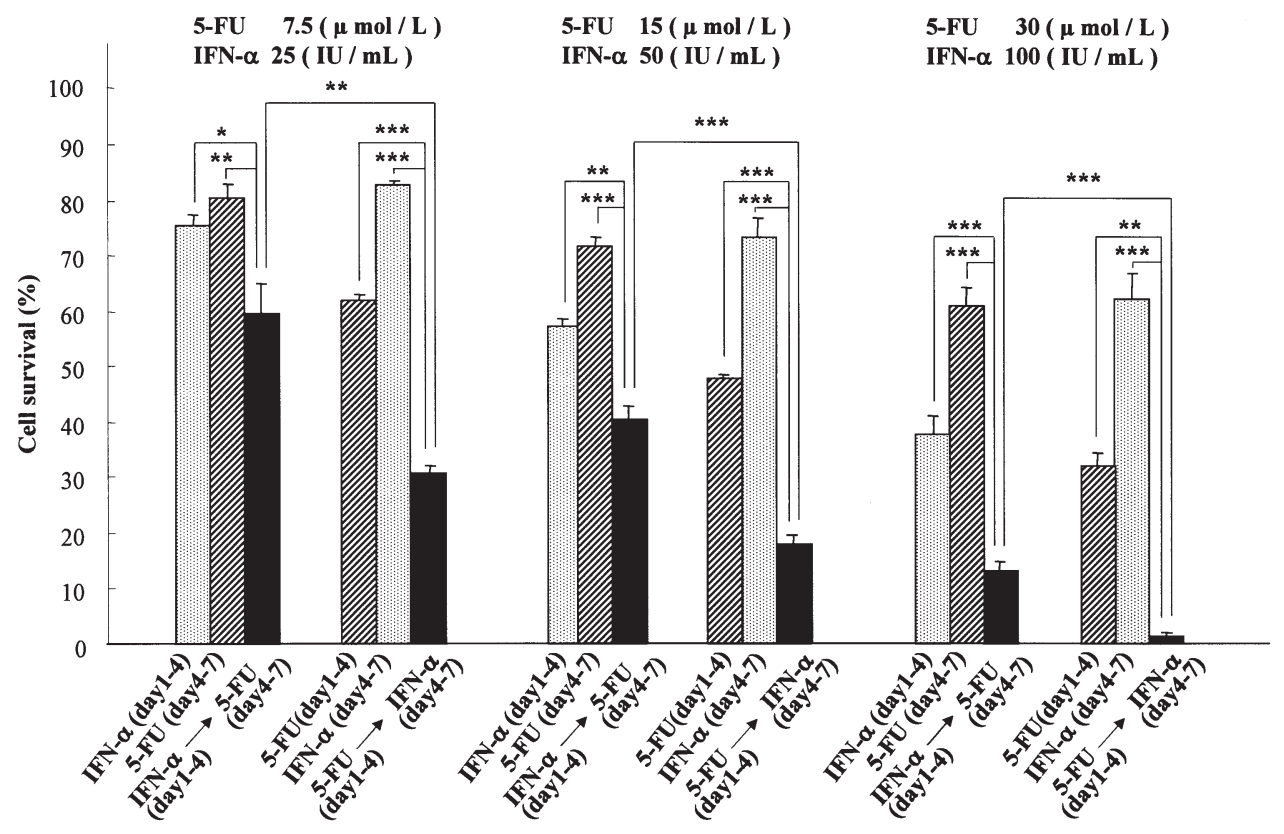

Figure 3. Schedule dependency of synergism of IFN- $\alpha$ and 5-FU. KYN-1 cells were seeded on day 0 and exposed to IFN- $\alpha$ or 5-FU for 3 days (day 1-4). On day 4, culture medium was removed and washed with PBS three times and fresh medium containing another drug was added. Cells were cultured for a further 3 days (day 4-7). The number of viable cells was estimated using the WST-8 assay. Experiments were carried out in triplicate independently. The columns show the mean value and bars represent SDs. Dotted column, IFN- $\alpha$ alone; striped column, 5-FU alone; solid column, sequential treatment of 5-FU and IFN- $\alpha$. ${ }^{*} \mathrm{P}<0.05,{ }^{* *} \mathrm{P}<0.01,{ }^{* * *} \mathrm{P}<0.001$; statistically significant difference between the indicated data points by Welch's test.

the IFN- $\alpha$-sensitive cell lines HAK-1B and KYN-1, while those in the other four HCC lines, which included both IFN- $\alpha$-sensitive and resistant lines, were only $5-40 \%$ of their levels in HAK-1B. As for IFNAR-1, the levels of IFNAR-2 mRNA were relatively higher in HAK-1B and KYN-1. Moreover, both IFN- $\alpha$-resistant cell lines, HAK-1A and KYN-2, had relatively lower levels of IFNAR-1 and IFNAR-2 mRNAs, while the other IFN- $\alpha$-sensitive cell lines had relatively higher levels of mRNA for both subunits.

Of the six factors regulating sensitivity to 5-FU, low levels of TS and DPD and high levels of OPRT, TP, UP and TK render cancer cells sensitive to 5-FU in in vitro assays. Cellular TS mRNA levels were relatively high in two 5-FUresistant lines, KYN-1 and KYN-3, while DPD mRNA levels were high only in KYN-1 cells. Cellular TP mRNA levels were relatively low in the 5-FU-resistant $\mathrm{KYN}-1$, but high in the 5-FU-sensitive HAK-1B cells. However, overall there was no clear association between the cellular mRNA levels of each factor and the 5-FU sensitivity of the six HCC lines.

Combined effect of IFN- $\alpha$ and 5-FU on six HCC cell lines. The isobologram method yielded three curves, Mode I, Mode IIa and Mode IIb. All of the data points for combined treatments against KYN-1 and KYN-2 cell lines, and three out of six data points for HAK-1A, fell in the area suggesting a synergistic effect and the other three points for HAK-1A cells were almost on the mode I curve (Fig. 2A and C). Therefore the combined effect of IFN- $\alpha$ and 5-FU on these three cell lines was judged to be synergistic. By contrast, all of the data points for combined treatments of HAK-1B, KYN-3, and KIM-1 cells fell within the envelope of additivity, and the combined effects on these cell lines were judged to be additive (Fig. 2D and F). Based on these results, we separated the six cell lines into two groups: the S-group, showing synergistic responses, and consisting of $\mathrm{KYN}-1, \mathrm{KYN}-2$, and HAK-1A, and the A-group, characterized by additive responses, and consisting of HAK-1B, KYN-3, and KIM-1.

As shown in Fig. 3, schedule-dependent interactions between IFN- $\alpha$ and 5-FU were examined using KYN-1 cells showing synergistic effect with simultaneous treatment of IFN- $\alpha$ and 5-FU. Sequential exposure to 5-FU followed by IFN- $\alpha$ showed much stronger antiproliferative effect than the reverse sequence at all tested concentration sets of 5-FU and IFN- $\alpha$.

Effect of IFN- $\alpha$ on protein expression of factors regulating 5-FU sensitivity. The metabolism of 5-FU is shown in Fig. 4A. The antitumor effects of 5-FU primarily depend on levels of its metabolic enzymes in in vitro study. We selected six enzymes, TS, DPD, OPRT, TP, UP and TK, that were reported to be closely associated with sensitivity and/or resistance to 5-FU. We examined their protein levels in these six cell lines when treated with IFN- $\alpha$ at $500 \mathrm{IU} / \mathrm{ml}$ for $48 \mathrm{~h}$ (Fig. 4B). The expression levels of TS, OPRT and TK were down-regulated after treatment with IFN- $\alpha$ for $48 \mathrm{~h}$, not only cell lines in the S-group, but also in the A-group. By contrast, treatment with IFN- $\alpha$ resulted in a 3 -fold increase in DPD protein level in KYN-3 cells. We also observed an upregulation of TP in IFN- $\alpha$ treated $\mathrm{KYN}-1$ and HAK-1A cells, both in the S-group, by 6.9 - and 2.8 -fold respectively. However, none of the six factors regulating sensitivity to $5-\mathrm{FU}$ was consistently modulated in response to IFN- $\alpha$ in all of the S-group or all of the A-group cell lines.

Effect of 5-FU on expression of IFNAR1 and IFNAR2 in six $H C C$ cell lines. The relative mRNA levels of IFNAR1 and 
A

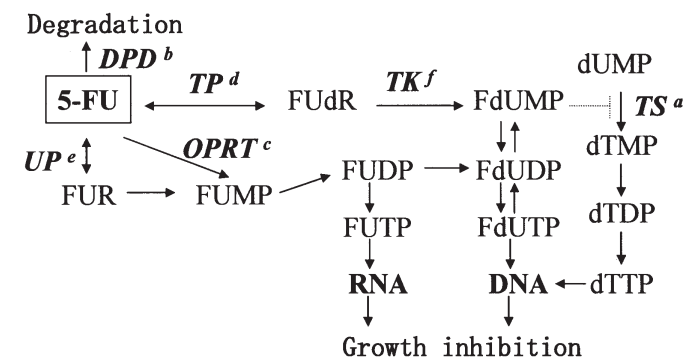

B

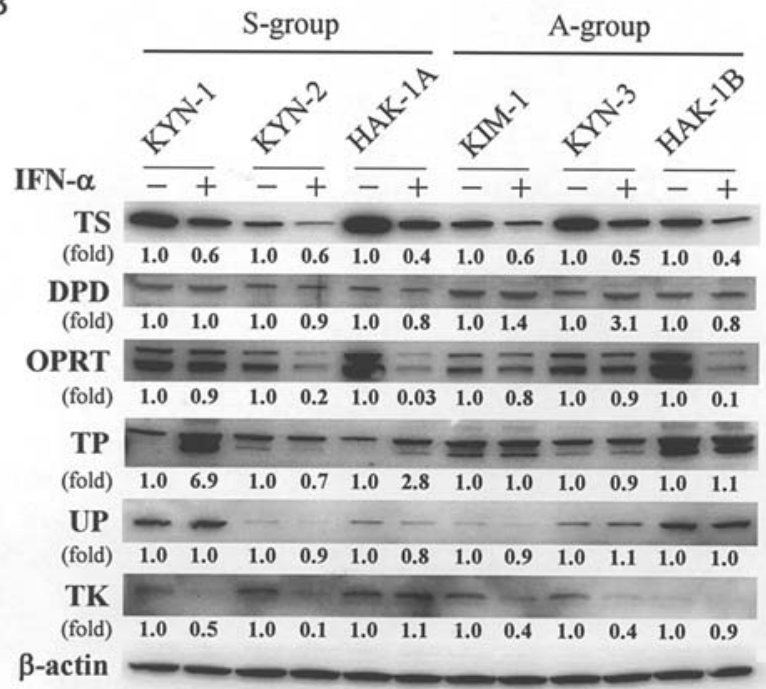

Figure 4. Effect of IFN- $\alpha$ on factors regulating sensitivity to 5-FU. (A) Metabolism of 5-FU. ${ }^{a} \mathrm{TS}$, thymidylate synthase; ${ }^{\mathrm{b}} \mathrm{DPD}$, dihydropyrimidine dehydrogenase; ' $\mathrm{OPRT}$, orotate phosphoribosyl transferase; ${ }^{\mathrm{d}} \mathrm{TP}$, thymidine phosphorylase; ' ${ }^{\mathrm{U}} \mathrm{P}$, uridine phosphorylase; ${ }^{\mathrm{T}} \mathrm{TK}$, thymidine kinase; FUdR, 5fluoro-2'-deoxyuridine; FdUMP, 5-fluoro-2'-deoxyuridine-5'-monophosphate; FdUDP, 5-fluoro-2'-deoxyuridine-5'-diphosphate; FdUTP, 5-fluoro-2'deoxyuridine-5'-triphosphate; FUR, 5-fluorouridine; FUMP, 5fluorouridine-5'-monophosphate; FUDP, 5-fluorouridine-5'-diphosphate; FUTP, 5-fluorouridine-5'-triphosphate. TS is a target enzyme of active metabolite FdUMP from 5-FU, and DPD inactivates 5-FU. OPRT, TP, UP and TK were concerned with conversion of 5-FU to its active form. Low levels of TS and DPD and high levels of OPRT, TP, UP and TK render cancer cells sensitive to 5-FU in in vitro assays. (B) Protein expression of six enzymes after 48 -h treatment with $500 \mathrm{IU} / \mathrm{ml} \mathrm{IFN}-\alpha$ were determined by Western blot analysis. Values underneath the bands represent the relative density to that of drug untreated cells, taken as 1.0. Cell lines in the S-group showed synergistic effect, and those in the A-group showed additive effect with combination of IFN- $\alpha$ and 5-FU.
IFNAR2 in 5-FU-treated HCC cells, compared to untreated cells, are shown in Fig. 5. In HAK-1A, KYN-1 and KYN-2 in the S-group, treatment with 5-FU induced an approximately 4-fold increase in IFNAR-1 mRNA levels when compared to untreated cells (Fig. 5A). By contrast, there appeared only a slight or no increase in IFNAR-1 mRNA in KIM-1, KYN-3, and HAK-1B in the A-group. We observed a 2.5- to 3-fold increase in IFNAR2 mRNA in KYN-1 and HAK-1A, but not in $\mathrm{KYN}-2$ in the S-group by 5-FU. By contrast, there appeared no increase of IFNAR2 mRNA by 5-FU in KIM-1, KYN-3, and HAK-1B cells in the A-group (Fig. 5B). Time-dependent kinetics for the expression of both type I IFN receptor subunits showed a marked increase in IFNAR1 and IFNAR2 mRNA levels at $3 \mathrm{~h}$ in KYN-1 cells, but not in KYN-3 cells when treated with 5-FU (Fig. 6A and B). In KYN-1 cells, Western blot analysis also showed an approximate 4-fold increase in protein levels of IFNAR1, $24 \mathrm{~h}$ after exposure to 5-FU (Fig. 6C). Treatment of KYN-1 cells with 5-FU induced an approximate 7-fold increase in IFNAR2 protein. In contrast, in KYN-3 cells in the A-group, the levels of the IFNAR2-related molecules R2 were not increased by 5-FU treatment (Fig. 6D).

Effect of knockdown of IFNAR1 and IFNAR2 by siRNA on antiproliferative effect of IFN- $\alpha$. We next examined whether cellular levels of IFNAR1 and/or IFNAR2 were closely associated with IFN- $\alpha$-induced antiproliferative effect in KYN-1 and KYN-3. Cellular levels of IFNAR1 and IFNAR2 proteins were markedly reduced by the relevant siRNAs, but not by scrambled RNAs (Fig. 7A). Moreover, the antiproliferative effect of IFN- $\alpha$ on both KYN-1 and KYN-3 cells was abrogated by knockdown of either IFNAR1 or IFNAR2, while the scrambled RNAs had no effect (Fig. 7B). Quantitative analysis of the cell survival curves of KYN-1 revealed that the knockdown of IFNAR1 and IFNAR2 increased the $\mathrm{IC}_{50}$ values for IFN- $\alpha$, by 7 -fold $(231 \mathrm{IU} / \mathrm{ml})$ and 5 -fold $(158 \mathrm{IU} / \mathrm{ml})$ respectively, compared to the $\mathrm{IC}_{50}$ values $(31 \mathrm{IU} / \mathrm{ml})$ for cells untreated with siRNAs and treated with scramble RNAs (Fig. 7C and Table III). In KYN-3 cells, the knockdown of IFNAR1 and IFNAR2 increased the $\mathrm{IC}_{50}$ values for IFN- $\alpha$ from $21 \mathrm{IU} / \mathrm{ml}$ for untreated control cells to over $1000 \mathrm{IU} / \mathrm{ml}$ respectively. The antiproliferative activity of IFN- $\alpha$
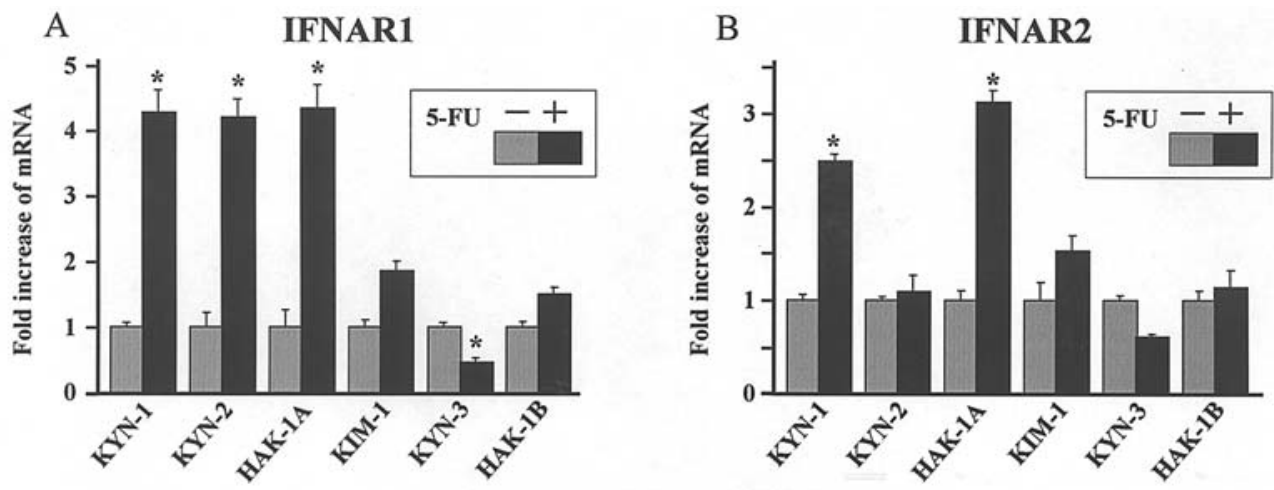

Figure 5. Expression of IFNAR1 and IFNAR2 mRNA, in HCC cells treated with $5.0 \mu \mathrm{mol} / 1$ 5-FU for 3 h. The increases in mRNA are shown relative to the initial level, taken as 1.0. Dotted and black columns show the mean mRNA levels in drug-untreated and 5-FU-treated cells, respectively. (A) IFNAR1, (B) IFNAR2. Determinations were carried out in triplicate, and bars represent the SDs. Experiments were repeated twice with essentially similar results. ${ }^{*}$ Difference is $>2$-fold and statistically significant by Welch's test $(\mathrm{P}<0.05)$ as compared with untreated cells. 
A

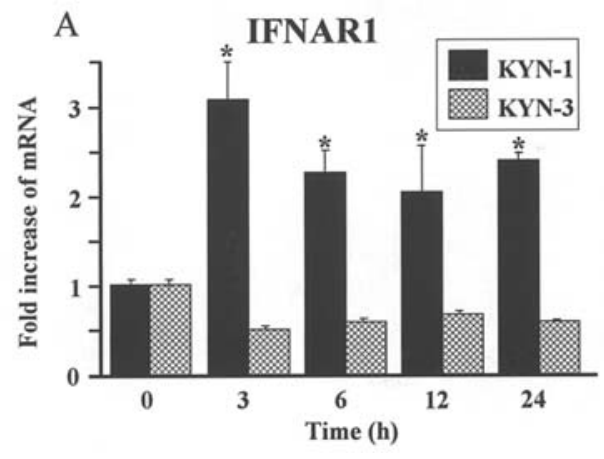

C

\section{IFNAR1}

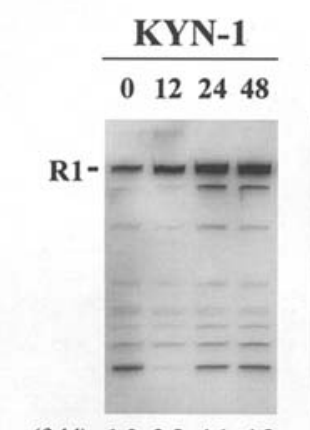

(fold) $1.0 \quad 2.8 \quad 4.1 \quad 4.3$

$\beta$-actin $-\infty$

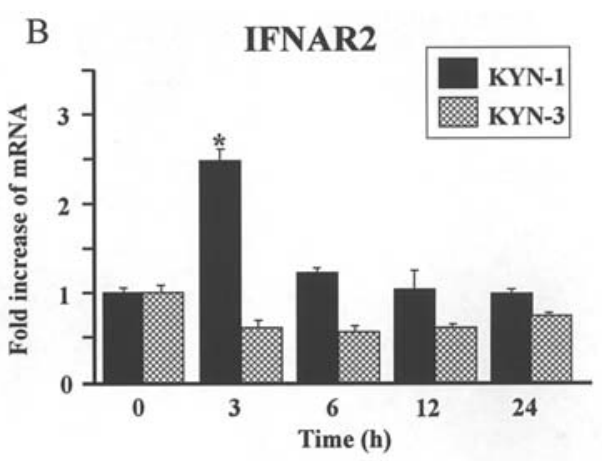

D

IFNAR2

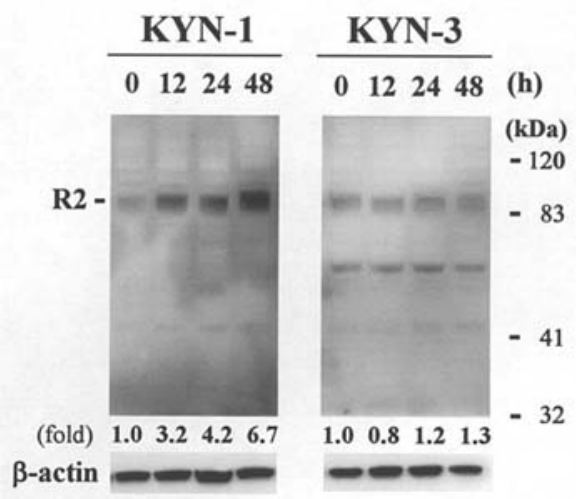

Figure 6. Time course of IFNAR1 and IFNAR2 mRNA and protein expression in KYN-1 and KYN-3 cells treated with $5 \mu$ mol/1 of 5-FU. Increases in mRNA expression levels for IFNAR1 (A) and IFNAR2 (B) are shown relative to the initial level, taken as 1.0, in KYN-1 and KYN-3 cells. Black columns represent the mean increase of mRNA levels in KYN-1 cells and meshed columns show increases in KYN-3 cells. Determinations were carried out in triplicate, and bars indicate the SD. *Difference is $>2$-fold and statistically significant by Welch's test $(\mathrm{P}<0.05)$, compared with initial level. Experiments were repeated twice with essentially similar results. (C) IFNAR1 protein expression in cells treated with 5-FU. R1 is an $\sim 110$-kDa band detected by Western blotting. (D) IFNAR2 protein expression in cells treated with 5-FU. R2 is an $\sim 100-\mathrm{kDa}$ band that may be the long form of IFNAR2. Experiments were repeated three times with essentially similar results.

in $\mathrm{KYN}-1$ and $\mathrm{KYN}-3$ cells was thus confirmed to be dependent on the expression levels of both IFNAR1 and IFNAR2.

\section{Discussion}

In this study, six independently established HCC cell lines were subjected to simultaneous treatment with 5-FU and IFN- $\alpha$ and classified into two groups on the basis of their antiproliferative activity according to isobologram analysis: KYN-1, KYN-2 and HAK-1A, in which the two drugs had a synergistic effect, were in the S-group, and HAK-1B, KYN-3 and KIM-1, in which the two drugs had an additive effect, were in the A-group. We further asked whether treatment with either 5-FU or IFN- $\alpha$ could modulate the expression of factors likely to be involved in the classification of the HCC cell lines into the S- or A-group.

We first determined cellular levels of mRNA and protein of TS, DPD, OPRT, TP, UP, and TK genes that are known to be involved in sensitivity to 5-FU (Table II and Fig. 4B). Basal levels of these cellular proteins in six cell lines used in this study were found to be comparable to their mRNA levels of these six enzymes. We examined whether exposure to IFN- $\alpha$ could modulate the protein expression levels of these six genes. Cellular expression levels of TS were not
Table III. IC $_{50}$ values of IFN- $\alpha$ against IFNARs reduced $\mathrm{KYN}-1$ and KYN-3 cell lines.

\begin{tabular}{lcc}
\hline & \multicolumn{2}{c}{$\mathrm{IC}_{50}(\mathrm{IU} / \mathrm{ml})$} \\
\cline { 2 - 3 } Treatment & $\mathrm{KYN}-1$ & $\mathrm{KYN}-3$ \\
\hline None & 31 & 21 \\
IFNAR1 knock down & 231 & $>1000$ \\
scramble of IFNAR1 siRNA & 34 & 19 \\
IFNAR2 knock down & 158 & $>1000$ \\
scramble of IFNAR2 siRNA & 28 & 20 \\
\hline
\end{tabular}

The IFNARs genes were silenced by Stealth ${ }^{\mathrm{TM}}$ RNAi (Invitrogen ${ }^{\mathrm{TM}}$ Life Technologies). KYN-1 and KYN-3 cells were treated with siRNAs and exposed to IFN- $\alpha$ for 5 days. $\mathrm{IC}_{50}$ values were calculated from dose-response curves shown in Fig. 7C.

significantly different in cell lines of the S- and A-group, suggesting that TS might not be a critical factor determining whether the combination effect is synergic or additive. None 
A

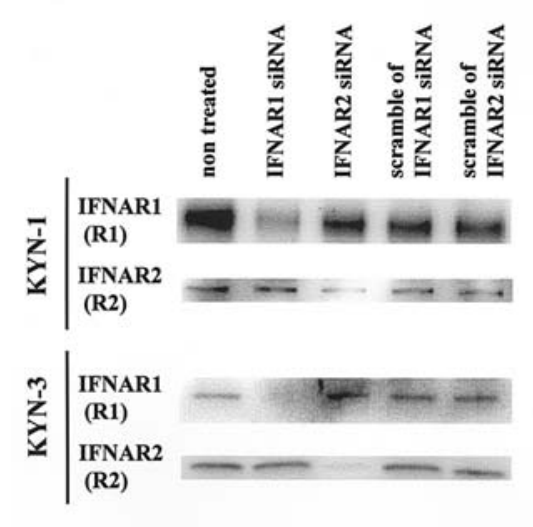

B

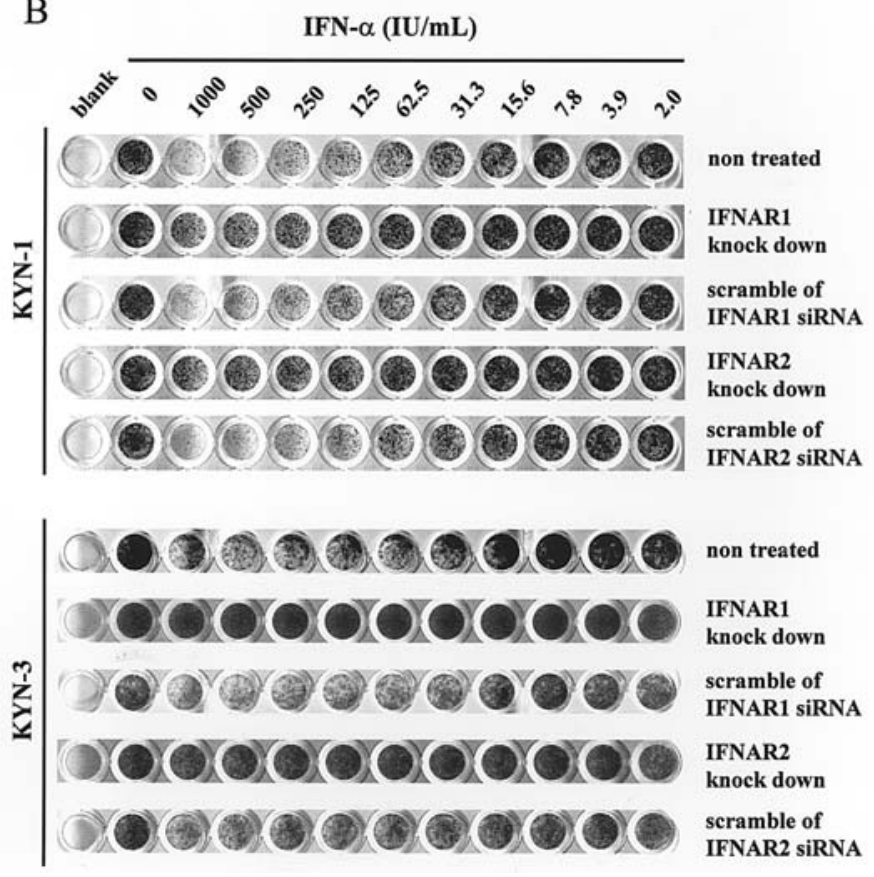

C

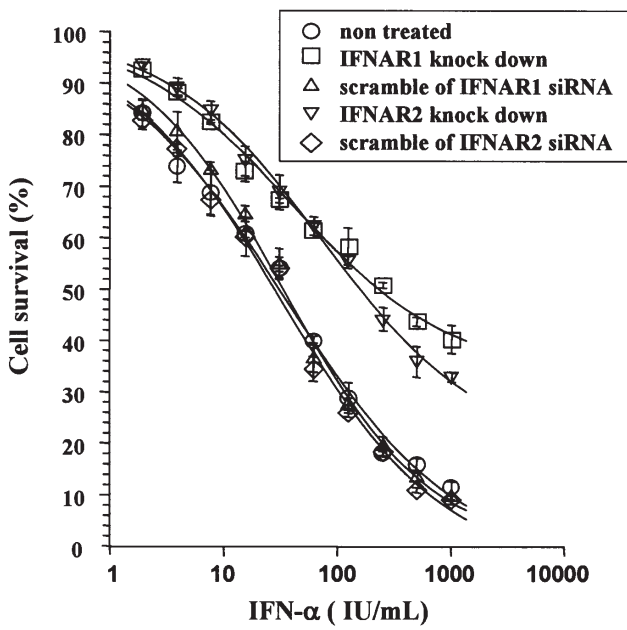

KYN-3

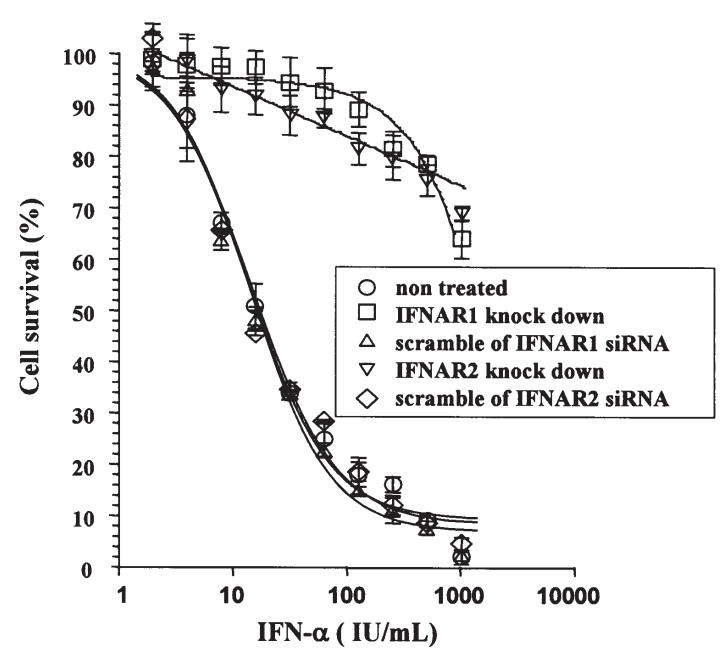

Figure 7. Dependency of antiproliferative activity of IFN- $\alpha$ on IFNAR1 and IFNAR2 expression. (A) Silencing of the IFNARs genes by siRNAs was confirmed by Western blotting. (B) KYN-1 and KYN-3 cells were treated with siRNAs and exposed to IFN- $\alpha$ for 5 days. Cells were stained by crystal violet. Assays were carried out in quadruplicate and one line of wells per condition of treatment is shown respectively. (C) Growth inhibitory effects of IFN- $\alpha$ on KYN-1 and KYN-3 cells pre-treated with siRNAs. Lines show the fitted curves of dose-response. Cell viability data is shown as means \pm SD ( $=4$ ). The differences between IFNARs siRNA pre-treated group and their respective scrambled control are statistically significant at all concentrations tested, by Welch's t-test $(\mathrm{P}<0.01)$. Experiments were repeated twice with essentially similar results. $\mathrm{IC}_{50}$ values are shown in Table III.

of the other genes were specifically down- or up-regulated in a similar manner in the 3 cell lines of the S- or A-group.

We next examined whether exposure to 5-FU could modulate expression levels of both mRNA and protein of IFNAR1 and IFNAR2. Knock down of IFNAR1 or IFNAR2 gene by its specific siRNA markedly desensitized the sensitivity of hepatic cancer cells to IFN- $\alpha$. This suggested that both IFNAR1 and IFNAR2 are closely associated with antiproliferative effect by IFN- $\alpha$. We further observed an approximate 4-fold increase in mRNA of IFNAR1 in the three cell lines in the $\mathrm{S}$ group, but no increase in the three cell lines in the Agroup, when treated with 5-FU. Western blot analysis showed an approximate 4-fold increase in IFNAR1 in a time-dependent manner and an approximate 7-fold increase in IFNAR2 in 5-FU-treated KYN-1 cells, but not in KYN-3. Treatment with 5-FU thus could induce specific expression of both IFNAR1 and IFNAR2 in HCC cell lines in the S-group, but not in the A-group. A relevant study by Kondo has reported that a combination of IFN- $\alpha$ and 5-FU strongly induced apoptosis in $\mathrm{HCC}$ cells in association with Bcl-2 family members by activation of IFNAR2 signal (33). Ota and colleagues have recently demonstrated a significant correlation of IFNAR2 expression and response rates in patients with HCC when treated with a combination of IFN- $\alpha$ and 5-FU (6). Collectively, 
up-regulation of IFNAR1 and IFNAR2 by 5-FU might play a pivotal role in synergism of IFN- $\alpha$ combined with 5-FU against HCC.

In conclusion, we present a novel finding that synergy between 5-FU and IFN- $\alpha$ in HCC cells is mediated through the 5-FU-induced up-regulation of the type I IFN receptor. The translation of this in vitro result into clinical application, particularly the identification of whether or not 5-FU upregulates the type I IFN receptor in a specific patient, would have a tremendous impact on the selection of the best treatment modality. Practical methods for determining the up-regulation of the type I IFN receptor, for selecting responders to combined IFN- $\alpha$ and 5-FU therapy should be the subject of further research. Moreover, our assay system using HCC cell lines could provide novel insights of practical significance, about other anticancer agents besides 5-FU, which could efficiently up-regulate the expression of the type I IFN receptor.

\section{Acknowledgements}

This study was supported in part by the 21 st Century COE Program for Medical Sciences supported by Ministry of Education, Culture, Sports, Science and Technology, Japan.

\section{References}

1. Cheung YC, Ko SF, Ng SH, Chan SC and Cheng YF: Survival outcome of lobar or segmental transcatheter arterial embolization with ethanol-lipiodol mixture in treating hepatocellular carcinoma. World J Gastroenterol 11: 2792-2795, 2005.

2. Ebara M, Okabe S, Kita K, Sugiura N, Fukuda H, Yoshikawa M, Kondo F and Saisho H: Percutaneous ethanol injection for small hepatocellular carcinoma: therapeutic efficacy based on 20-year observation. J Hepatol 43: 458-464, 2005

3. Kawamoto C, Ido K, Isoda N, Hozumi M, Nagamine N, Ono K, Sato Y, Kobayashi Y, Nagase G and Sugano K: Long-term outcomes for patients with solitary hepatocellular carcinoma treated by laparoscopic microwave coagulation. Cancer 103: 985-993, 2005.

4. Tateishi R, Shiina S, Teratani T, Obi S, Sato S, Koike Y, Fujishima T, Yoshida H, Kawabe T and Omata M: Percutaneous radiofrequency ablation for hepatocellular carcinoma. An analysis of 1000 cases. Cancer 103: 1201-1209, 2005.

5. Llovet JM: Updated treatment approach to hepatocellular carcinoma. J Gastroenterol 40: 225-235, 2005.

6. Ota H, Nagano H, Sakon M, Eguchi H, Kondo M, Yamamoto T, Nakamura M, Damdinsuren B, Wada H, Marubashi S, Miyamoto A, Dono K, Umeshita K, Nakamori S, Wakasa K and Monden M: Treatment of hepatocellular carcinoma with major portal vein thrombosis by combined therapy with subcutaneous interferon-alpha and intra-arterial 5-fluorouracil; role of type 1 interferon receptor expression. Br J Cancer 93: 557-564, 2005.

7. Sakon M, Nagano H, Dono K, Nakamori S, Umeshita K, Yamada A, Kawata S, Imai Y, Iijima S and Monden M: Combined intraarterial 5-fluorouracil and subcutaneous interferon-alpha therapy for advanced hepatocellular carcinoma with tumor thrombi in the major portal branches. Cancer 94: 435-442, 2002.

8. Miyamoto A, Umeshita K, Sakon M, Nagano H, Eguchi H, Kishimoto S, Dono K, Nakamori S, Gotoh M and Monden M: Advanced hepatocellular carcinoma with distant metastases, successfully treated by a combination therapy of alpha-interferon and oral tegafur/uracil. J Gastroenterol Hepatol 15: 1447-1451, 2000.

9. Stuart K, Tessitore J and Huberman M: 5-Fluorouracil and alpha-interferon in hepatocellular carcinoma. Am J Clin Oncol 19: 136-139, 1996.

10. Dash S, Prabhu R, Hazari S, Bastian F, Garry R, Zou W, Haque S, Joshi V, Regenstein FG and Thung SN: Interferons alpha, beta, gamma each inhibit hepatitis $\mathrm{C}$ virus replication at the level of internal ribosome entry site-mediated translation. Liver Int 25: 580-594, 2005
11. Theofilopoulos AN, Baccala R, Beutler B and Kono DH: Type I interferons (alpha/beta) in immunity and autoimmunity. Annu Rev Immunol 23: 307-336, 2005.

12. Bekisz J, Schmeisser H, Hernandez J, Goldman ND and Zoon KC: Human interferons alpha, beta and omega. Growth Factors 22 243-251, 2004.

13. Rosewicz S, Detjen K, Scholz A and von Marschall Z: Interferon-alpha: regulatory effects on cell cycle and angiogenesis Neuroendocrinology 80: 85-93, 2004.

14. Tedjarati S, Baker CH, Apte S, Huang S, Wolf JK, Killion JJ and Fidler IJ: Synergistic therapy of human ovarian carcinoma implanted orthotopically in nude mice by optimal biological dose of pegylated interferon alpha combined with paclitaxel. Clin Cancer Res 8: 2413-2422, 2002.

15. Roisman LC, Jaitin DA, Baker DP and Schreiber G: Mutational analysis of the IFNAR1 binding site on IFNalpha2 reveals the architecture of a weak ligand-receptor binding-site. J Mol Biol 353: 271-281, 2005

16. Lamken P, Gavutis M, Peters I, van der Heyden J, Uze G and Piehler J: Functional cartography of the ectodomain of the type I interferon receptor subunit ifnar1. J Mol Biol 350: 476-488, 2005.

17. Fujiwara D, Hino K, Yamaguchi Y, Kubo Y, Yamashita S, Uchida K, Konishi T, Nakamura H, Korenaga M, Okuda M and Okita K: Type I interferon receptor and response to interferon therapy in chronic hepatitis $\mathrm{C}$ patients: a prospective study. $\mathrm{J}$ Viral Hepat 11: 136-140, 2004

18. Wagner TC, Velichko S, Chesney SK, Biroc S, Harde D, Vogel D and Croze E: Interferon receptor expression regulates the antiproliferative effects of interferons on cancer cells and solid tumors. Int J Cancer 111: 32-42, 2004.

19. Ismail A, van Groeningen CJ, Hardcastle A, Ren Q, Aherne GW, Geoffroy F, Allegra CJ and Grem JL: Modulation of fluorouracil cytotoxicity by interferon-alpha and -gamma. Mol Pharmacol 53: 252-261, 1998.

20. Danhauser LL, Freimann JH Jr, Gilchrist TL, Gutterman JU, Hunter CY, Yeomans AC and Markowitz AB: Phase I and pharmacokinetic study of infusional fluorouracil combined with recombinant interferon alpha- $2 \mathrm{~b}$ in patients with advanced cancer. J Clin Oncol 11: 751-761, 1993.

21. Schwartz EL, Hoffman M, O'Connor CJ and Wadler S Stimulation of 5-fluorouracil metabolic activation by interferon- $\alpha$ in human colon carcinoma cells. Biochem Biophys Res Commun 182: 1232-1239, 1992.

22. Yee LK, Allegra CJ, Steinberg SM and Grem JL: Decreased catabolism of 5-fluorouracil in peripheral blood mononuclear cells during therapy with 5-fluorouracil, leucovorin and interferon alpha-2a. J Natl Cancer Inst 84: 1820-1825, 1992.

23 Yao Y, Kubota T, Sato K, Takeuchi H, Kitai R and Matsukawa S: Interferons up-regulate thymidine phosphorylase expression via JAK-STAT-dependent transcriptional activation and mRNA stabilization in human glioblastoma cells. J Neurooncol 72 : 217-223, 2005.

24. Dou J, Iwashita Y, Sasaki A, Kai S, Hirano S, Ohta M and Kitano S: Consensus interferon enhances the anti-proliferative effect of 5-fluorouracil on human hepatoma cells via downregulation of dihydropyrimidine dehydrogenase expression. Liver Int 25: 148-152, 2005.

25. Eguchi H, Nagano H, Yamamoto H, Miyamoto A, Kondo M, Dono K, Nakamori S, Umeshita K, Sakon M and Monden M: Augmentation of antitumor activity of 5-fluorouracil by interferon alpha is associated with up-regulation of p27Kip 1 in human hepatocellular carcinoma cells. Clin Cancer Res 6: 2881-2890, 2000.

26. Murakami T: Establishment and characterization of human hepatoma cell line (KIM-1). Acta Hepatol Jpn 25: 532-539, 1984.

27. Yano H, Kojiro $M$ and Nakashima T: A new human hepatocellular carcinoma cell line (KYN-1) with a transformation to adenocarcinoma. In Vitro Cell Dev Biol 22: 637-646, 1986.

28. Yano H, Maruiwa M, Murakami T, Fukuda K, Ito Y, Sugihara S and Kojiro M: A new human pleomorphic hepatocellular carcinoma cell line, KYN-2. Acta Pathol Jpn 38: 953-966, 1988.

29. Murakami T, Maruiwa M, Fukuda K, Kojiro M, Tanaka M and Tanikawa K: Characterization of a new human hepatoma cell line (KYN-3) derived from the ascites of the hepatoma patient. Proceedings of the Japanese Cancer Association. Jpn J Cancer Res 292, 1988

30. Yano H, Iemura A, Fukuda K, Mizoguchi A, Haramaki M and Kojiro M: Establishment of two distinct human hepatocellular carcinoma cell lines from a single nodule showing clonal dedifferentiation of cancer cells. Hepatology 18: 320-327, 1993. 
31. Ishiyama M, Miyazono Y, Sasamoto K, Ohkura Y and Ueno K: A highly water-soluble disulfonated tetrazolium salt as a chromogenic indicator for NADH as well as cell viability. Talanta 44: 1299-1305, 1997.

32. Steel GG and Peckham MJ: Exploitable mechanisms in combined radiotherapy-chemotherapy: the concept of additivity. Int J Radiat Oncol Biol Phys 5: 85-91, 1979.
33. Kondo M, Nagano H, Wada H, Damdinsuren B, Yamamoto H, Hiraoka N, Eguchi H, Miyamoto A, Yamamoto T, Ota H, Nakamura M, Marubashi S, Dono K, Umeshita K, Nakamori S, Sakon M and Monden M: Combination of IFN-alpha and 5fluorouracil induces apoptosis through IFN-alpha/beta receptor in human hepatocellular carcinoma cells. Clin Cancer Res 11: 1277-1286, 2005. 